\title{
University Exceptional Admission during the Republic of China
}

\author{
Li Tao ${ }^{1}$ \\ ${ }^{1}$ Faculty of Education, Southwest University, Chongqing, China \\ Correspondence: Li Tao, Faculty of Education, Southwest University, No2 Tiansheng Road, Chongqing, China. \\ Tel: 86-136-3831-7583. E-mail: Lit1983@163.com
}

Received: May 31, 2014 Accepted: July 2, 2014 Online Published: July 29, 2014

doi:10.5539/hes.v4n4p18 URL: http://dx.doi.org/ hes.v4n4p18

\begin{abstract}
The stories of many universities' exceptive admission during the republic period of China were widely circulated. The typical example of these universities' exceptional admission was the very product of special historical condition, which had its own characteristics, but also conforms to the general rule, so it can be cited .To select special talents that adapted to contemporary era, right of enrollment should be returned to university, living space be given to traditional education and standardized tests be reformed.
\end{abstract}

Keywords: the Republic of China, university, exceptional admission

When it comes to Sinology master, people are always longing to the scholars during the Republic of China; When it comes to the college entrance examination reform, people can not help but would relish a separate enrollment in university during the Republic of China; And when it comes to exceptional admission, people can't help but thinking of QianZhongshu, ZangKejia, WuHan, etc. Now there are two basic views toward university exceptional admission of the Republic of China in academia: one is that the exceptional admission is the product of special historical condition so it can't be promoted widely, what is more some of that has been misrepresented, blindly reference may even affect educational fairness; Another takes the view that exceptional admission of the republic of China was a real and reliable and of great significance and value that it can be reference for today's college entrance examination reform. The focus that two sides debate is the truth and feasibility of exceptional admission of Republic of China.

\section{Introduction}

\subsection{The Widespread Exceptional Admission Story Is with Legends to Some Extent}

Sorting out the historical truth is the precondition to analyze the facts and sum up experience and lessons. Some scholars believe that Qian's and Wu's exceptional admission is not the result of aptitude test election, but only a special case of self-enrollment. Could such a special case be applied widely, and be established as one of the college entrance examination system, which is worthy of in-depth analysis (Zhang, 2011). Some other scholars believe that although the story of Wu's exceptional admission by Tsinghua University is good, but not historical facts. On the contrary, it shows that the Tsinghua University's talent selection during the Republic of China had a rule to base, laws to follow and grid to defend, same as the special talent selection (Liu, 2010). According to this point above mentioned, university's exceptional admission during the Republic of China is just particular case and there is a gist. So it doesn't belong to abnormality and has no extension.

Exceptional admission refers to certain aspects of the candidate isn't up to the school's admission criteria, but other aspects are outstanding and prominent so school break the routine to accept them as special talents. First, take a popular story for example, Wu first entered himself for an examination of the history department of Peking University in 1931, and got a full mark in English literature and history, while got zero in math, he failed. Then he enters oneself for an examination of Tsinghua, test scores are exactly the same. And the two schools have rules that candidates with a grade of zero points can't be accepted. At last he was admitted by Tsinghua for his outstanding achievement at history. In fact, Wu was attending a transfer test. National Tsinghua University Undergraduate Enrollment Brochure of 1932 stipulates that transfer students are subject to the university transfer experiment, the experiment is held at the same time with the first grade entrance test. And the second grade of Department of history should test: party righteousness, the Chinese, English, the Chinese general history, western history, any one of university general physics, general chemistry, ordinary biology and ethics (Anonymous, 1931). Therefore, Wu got zero grades at math in Tsinghua scotched. Besides, Tsinghua university 
transfer student admission criteria in 1931 ruled: the grand average score should be more than 60 points, and the average score between Chinese and English must pass 50 in History Department. Transfer student special admission criteria: those whose total average score is more than 50 , special subject's average score is more than 65 points and scores 40 points or more but less than 50 in Chinese and English may be addressed by the head of the department to discuss special admission (Anonymous, 1934).

Although we didn't find the score that Wu Han's entrance exam to Tsinghua University, from his great score in the entrance exam to Peking University, at that time, Wu Han's scores in the entrance exam to Tsinghua University was enough to reach the level that Tsinghua required in the normal examination. There was no necessity to be admitted by special admission. Therefore, in the Math examination in the admission to Tsinghua University, his score was 0 , it was inaccurate to say Wu Han was specially admitted. But we could not deny the fact that Tsinghua attached great importance to the talents. In 1912, Wen Yiduo took part in the entrance examination to Tsinghua, the qualifying exam was held in Wuchang, the subjects included history, geography, math, English. He got relatively flat scores in these exams. But his paper entitled Duo Wen Que Yi was praised greatly by the examiners. This paper was in association with his name. The key point was he imitated the writing style of Liang Qichao, which was the most popular style at that time. It surprised the examiner because this paper was written by a young man. As a result, this outstanding paper made Wen Yiduo rank NO.1 in the examination. By this way, he got the qualification to go to Beijing to attend the second examination. In the second examination, he was admitted as the second (Wen, 1992). If there was no except examination, he could not have the chance to attend the second examination. Wen Yiduo was not only the beneficial owner of except admission, but also continued such tradition. In 1930s, Zang Kejia applied for Qingdao University. As the admission to Qingdao University was very strict, when he received the admission letter, he was very shocked. His Chinese was 98 while his math was 0 . Zang Kejia thought "It must be the three sentences that impressed Wen Yiduo. In the title, he wrote: we were always coming up with magic light in life, but who treat the magic light as the magic light would fall into a deep sea". When Wen Yiduo read this, he believed he had found an outstanding student, who could be further cultivated (Sun, 2000). Not only Tsinghua had this tradition, but Peking University had it, too. Hu Shi left a special eye to the students who were good at history and literature, such as Luo Jialun, Wu Han, Zhang Chonghe, Ye Man etc. (Table 1) Such tradition in Peking University was carried forward by Luo Jialun, Jiang Menglin1 etc.

\subsection{Secondly, We Measure the above Case by Peking University and Tsinghua University Admissions Standards}

Examination committee for the 1929 Beijing university undergraduate course of new standard is: the ones whose total points of Chinese, and foreign language over 120 and every other subject scores not less than 10; Preparatory new second-round exam admission criteria: 1) Those who are any subject of five sores zero won't be admitted. 2) Those whose total scores less than 150 won't be admitted. 3) Those who conforms to one of the above two situations while his first exam is special excellent can be accepted after deliberation(one course grades over 90;two courses grades over 70;three courses grades over 60)" (Wang, 2000). According to this standard, Luo Jialun and Zhang Chonghe could not be admitted under normal circumstances since they all got 0 in math. Therefore, those people were exceptionally admitted to Peking University rather than special case. Then look at Tsinghua university's undergraduate recruitment standards: freshmen admission criteria of 1929 was that the grand average score should be over 40 and the average score of Chinese, English and math should be more than 40, while standards of 1930 ruled that the grand average score should be over 45 and the average score of Chinese, English and math should be more than 49. Transfer student special admission standards of 1929 ruled that those whose grand average score is over 40 , specialized subjects is extremely excellent and one subject of Chinese and English scores less than 50 but more than 40 can be addressed by the head of the department to discus discuss special admission, standards of 1930 ruled that those whose grand average score is over50,specialized subjects is extremely excellent and one subject of Chinese and English scores less than 50 but more than 40 can be addressed by the head of the department to discuss special admission." (Anonymous, 1934). According to this standard, Qian Zhongshu got 15 and Ji Xianlin got 4 at math, but their Chinese and English are excellent and the grand average score was over 60.so they didn't belong to Exceptional Admission cause their grades was within the limits of Tsinghua. Tsinghua's recruitment standards left living space to special talents for it didn't limit the minimum points.

\subsection{Actually, Peking University's Exceptional Admission Broke Through The School's Minimum Admission Criteria, and Tsinghua Exceptional Admission Seemingly did not Break Through the School's Admission Criteria, Essentially It Left Living Space to Special Talents from the System}

In fact, both two universities were aimed to promote the development of talents but took different measures, one broke old system, and one built new system. 
Table 1. Exceptional admission cases in the republic of China

\begin{tabular}{|c|c|c|c|c|c|}
\hline Time & Weird talents & Teacher & Scores & School & Annotation \\
\hline 1912 & Wen Yiduo & None & $\begin{array}{l}\text { Chinese was best while } \\
\text { others were flat. }\end{array}$ & $\begin{array}{l}\text { Tsinghua } \\
\text { University }\end{array}$ & Admitted as probationer \\
\hline 1917 & Luo Jialun & $\begin{array}{l}\text { Cai } \\
\text { YuanpeiHu } \\
\text { Shi }\end{array}$ & $\begin{array}{c}\text { Chinese was } 100 \text { while } \\
\text { math was } 0 .\end{array}$ & $\begin{array}{l}\text { Peking } \\
\text { University }\end{array}$ & - \\
\hline 1929 & Qian Zhongshu & $\begin{array}{l}\text { Luo } \\
\text { Jialun }\end{array}$ & $\begin{array}{l}\text { Chinese was excellent; } \\
\text { English was } 100 \text { while } \\
\text { math was } 15 .\end{array}$ & $\begin{array}{l}\text { Tsinghua } \\
\text { University }\end{array}$ & - \\
\hline 1930 & Ji Xianlin & NONE & $\begin{array}{l}\text { Chinese and English were } \\
\text { better while math was } 4 .\end{array}$ & $\begin{array}{c}\text { Tsinghua } \\
\text { University, } \\
\text { Peking } \\
\text { University }\end{array}$ & $\begin{array}{l}\text { Admitted by Tsinghua } \\
\text { and Peking at the same } \\
\text { time }\end{array}$ \\
\hline 1930 & Zang Kejia & Wen Yiduo & $\begin{array}{c}\text { Chinese was } 98 \text { while } \\
\text { math was } 0 .\end{array}$ & $\begin{array}{l}\text { Qingdao } \\
\text { University }\end{array}$ & $\begin{array}{l}\text { Took part in the } \\
\text { examination using } \\
\text { someone else's diploma }\end{array}$ \\
\hline 1931 & Wu Han & Hu Shi & - & $\begin{array}{l}\text { Tsinghua } \\
\text { University }\end{array}$ & $\begin{array}{c}\text { Took part in the transfer } \\
\text { tests of Tsinghua and } \\
\text { Peking }\end{array}$ \\
\hline 1934 & Zhang Xuan & Hu Shi & $\begin{array}{l}\text { Chinese was } 100 \\
\text { while math was } 0 .\end{array}$ & $\begin{array}{l}\text { Peking } \\
\text { University }\end{array}$ & Admitted as probationer \\
\hline 1935 & Ye Man & Hu Shi & $\begin{array}{l}\text { Better in literature while } \\
\text { others were poor }\end{array}$ & $\begin{array}{c}\text { Peking } \\
\text { University }\end{array}$ & Admitted as probationer \\
\hline
\end{tabular}

\section{The Elaborate Analysis about Exceptional Admission}

\subsection{The Features of University's Exceptional Admission during the Republican Period of China}

There were following features about university exceptional admission during the Republican period of China.

\subsubsection{These Exceptionally Recruited Students by Universities Had Talents for Literature and History}

They were excellent special talents in the realm of literature and history but few in natural science or social science, which was determined by the development of academics and education at that time. Both modern classification system of sciences and modern science were introduced to our country from the West. And our elementary education was weak then. Most of the special talents firstly received education of traditional culture at home school with a private tutor (called Si Shu in Chinese) in their early years, then went to modern west-style school with learning some easy level of science and foreign language, but the rest of them even didn't enter a modern school and they taught themselves. Generally speaking, it's harder just by self-teaching to success in such natural science subjects as mathematics, physics or chemistry than in Chinese traditional literacy.

\subsubsection{Students Was Recruited Exceptionally with the Method of Examinations}

All students recruited with an exception needed success in exams. These exams were to select students who surpassed the ordinary at wisdom. Nevertheless, few students who had excellent performance in morality, P.E. or art could be sent on recommendation to universities, which reflected that universities in the Republic of China carried on the tradition of imperial examination to recruit student. The phenomenon seemed to indicate that people's belief in the objective and fair examination was still strong, and they feared that sending students on recommendation would destroy that kind of objectiveness. Judging from the previous statement, we could find that the exceptional admission or the student recruitment at that time was not so perfect for the over limited exams' contents. Absolutely, lack of an objective standard for students' performance in morality, P.E. or art was a reason to limit the exams' contents.

2.1.3 Probation Period Was Kept to Continually Observe the Exceptionally Recruited Students, which Guaranteed the Students' Quality. Recruited Students were Required to Study on Probation

In this way, on the one hand, a special talent got a chance to study in university; on the other hand, a limited period was used to confirm that the students recruited with an exception were real special talents. 
2.1.4 The Cases of Exceptional Admission Mostly Took Place in Peking University and Tsinghua During the 1920 s and 1930s

To some point, exceptional admission might be called "dispersive case". This period witnessed the New Culture Movement (around the time May $4^{\text {th }}$ Movement in 1919), so splendid thoughts occurred in universities. By the way, universities had a full right to enroll students independently rather than educational administration totally intervened. People like Cai Yuanpei, Hu Shih, Wen Yiduo, Luo Jialun etc. were the pioneers of the New Culture Movement and they insisted on a spirit of western liberalism while dealing with students enrollment work and focused on a student himself, and this tradition was remained from one generation to another.

\subsection{The Reasons for Frequent Cases of Exceptional Admission in the Republican China}

\subsubsection{Universities had a Right to Test and Enroll Students}

Most universities in the Republic of China carried out the system of recruiting students independently before 1939. Government just made some necessary principles rather than supervised the universities strictly. The right of testing and enrolling students was released to universities from government, which was an essential characteristic of students-enrollment then. Universities had a total right on anything about students' recruitment, for instance, making an enrollment plan, publishing advertisement, editing test paper, arranging tests, making standards for admission and announcing the list of admitted students, and so on. Why universities didn't take this right for renting-seeking? One of critical reasons was the public and fair system of admission. A university admission test committee was established in charge of test or recruitment jobs. A general regulation of enrollment, admission criteria and admission list would be published in authoritative newspapers. For example, regulations from the Regulation of National Chung Cheng University of Admission Committee put, "First article, this admission committee is established according to the $28^{\text {th }}$ article of the Regulation. The second, the members of the admission committee include president, Dean of Studies, Dean of General Affairs, deans of schools, heads of departments, and dean of registration. President is appointed with chairman of the committee. When president is absent, Dean of Studies will deal with jobs as acting chairman. The third, the responsibilities of the committee as follows, 1) Draft general regulation of enrollment. 2) Check the number of new students and transfer students. 3) Decide where to go for new students and to choose someone responsible for details. 4) Budget for recruiting students. 5) Recommend person for editing test papers or as exam proctors. 6) Make criteria for recruiting new students and decide the final list. 7) Confirm and report the quality of new students. 8) Decide anything else about student recruitment. The fourth, the Regulation 's implement date is determined by approval of school administrative meeting" (Anonymous, 1941). Therefore, independent right on selecting students made universities free to decide what type of students they needed in accordance with the demands of development, meanwhile, made this kind of selecting fair, which was a crucial reason to keep universities special and in high tone at that time.

\subsubsection{Educational Development in the Republic of China Didn't Fall into a Pattern}

Elementary education development was weaker than other stages'. The number and the quality of students with insufficient knowledge in Middle schools and primary schools won't satisfy people. It was not strange to hear that somebody got a zero in university entrance examination or even so he still was admitted to a university. But that kind of student was lacking in science knowledge particularly. Actually the similar problem, natural science dulled in development, also could be found in university. Therefore with the help of theories of western humanities and social sciences, explaining the Chinese traditional scholarship became universities' mission to revitalize China. In addition, humanities and social sciences required less cost and equipment, but the influence produced was stronger. All of these made exceptional admission a sensation.

2.2.3 Universities Pursues the Spirits of Independence and Freedom. Scholars like Cai Yuanpei, Hu Shih, and Luo Jialun etc.

Brought western independence and liberalism in Chinese universities by the New Culture Movement and sanitizes these western spirits. These scholars treated talented person as driving force of university development. No matter how familiar or not, if one had real ability, they would spare no effort to recommend him. For instance, $\mathrm{Hu}$ Shih was to Wu Han and Luo Jialun what Luo Jialun was to Qian Zhongshu. These scholars won't be partial to somebody out of interpersonal relationship. A long-term habit led to a tradition of exceptional admission and Peking University and Tsinghua developed this tradition. Apparently, exceptional admission depended on the system of running university by professors and democratic management. Running university by professors instead of by bureaucrats guaranteed the scientific and democratic recruiting special talents for universities.

2.2.4 There had not Been a Sound Examination System 
Firstly, secondary school general examination system didn't totally work, which led to a difficulty in guarantee the quality of graduates from secondary schools, to an excessive ratio on university applicants with an equivalent education level and to even many people used a fake school diploma to apply for university. In positive, these conditions created a chance to some special talents, such as Zang Kejia and Zhang Chong without a real secondary school diploma. This leak must be made by history. These phenomenons were not rare. For example, "in the autumn of 1930, after new term began, Qingdao University managers found many students who had been admitted use a fake school diploma when applied for university." "The amount of students who were forced to drop out was enormous." (Li, 1983) which caused the storm of students' classes boycott. Secondly, setting test question and grading test paper hadn't been standardized, so the test liability and validity was not so good. Most of the time, test paper came from a famous professor. For instance, in $1935 \mathrm{Hu}$ Shih wrote in diary that "set questions for university entrance examination" (Hu, 2001) in 1932 Chen Yinque set questions in Chinese test for Tsinghua entrance examination. The test questions from these professors just included composition-writing and ancient Chinese prose-translating, which covered limited contents, with the difficulty hard to control and the general validity not so good. This kind of test questions had such problems as hard to adapt to the standard of development of western science. This way, however, was suitable for selecting talents good at Chinese traditional academics. Therefore, there was a dispute between two groups; one group supported to replace this paper-writing test in a new one, another was opposite to. "An incident of Chinese couplets-making in Tsinghua entrance examination" exactly showed the dispute.

\section{Postscript Part}

In a word, some universities in the Republican period of China selected special talents by exceptional admission, which made most of them become masters. Although university exceptional admission was created by special history condition in the Republican period of China, it also accorded with the general rule and could afford us lessons to reform college entrance examination.

\subsection{Return the Right of Admitting Students by Examination to University and Strictly Regulate the Procedure}

From no matter what an standpoint of legislation or reality, the right of admitting students by examination for university is one of crucial rights and government, including educational administration, has no reason to intervene. It is necessary to change that the right of recruiting students is under control of government and that the old ideas of government should control education. It is returning that the right a university should have rather than giving or giving in charity. The question need to discuss is not if the right should be returned but how to make the right work. If without self dependent university, without the system of running university by professors and democratic management and without the open and transparent examination process, returning the right of recruiting students equals to undermine fairness to everyone in university entrance. At present, there are many problems about universities experimental independent enrolment, because universities have not totally recovered the tradition of "freedom and democracy". Independent enrolment influenced by power and money will not come to a satisfied result. It is worried that once the experiment of independent enrolment fails, university will go back to the old way of unified enrolment rather than consider how to make university recover the tradition of "freedom and democracy".

\subsection{Create Loose Development Environment for Foundational Education and Loosen up the Limit to University Entrance Qualification}

Many recruited students by exceptional admission became masters in the Republic of China. And most of them received an education of "Read Chinese Classics" in early years, which was an important reason why they could be masters. "Wen Yiduo went to a home school with a private tutor (called Si Shu in Chinese) at five years old, reading The Three-Character Classic, Children's Necessary Reading, cry's and The Four Books (including The Great Learning; The Doctrine of the Mean; The Analects of Confucius; Mercies) (Wen, 1992) . "Wu Han's father was strict with him, requiring him to read Yu Pi Tong Jian and even to recite some paragraphs of it at his 11." (Su, S. B, 1998). Therefore, there should be a dialectic point view about reading Chinese Classics. It would discuss how to read Chinese Classics in a scientific and rational way rather than whether to read classics. Because Education Law can't permit students to receive compulsory education at Si Shu and parents also can't be permitted to teach their own children by themselves at home, there is a strong appeal for living-space of traditional education. Traditional education is not a monster or destroyer, and it can be positive in some aspects. In addition, there is a need to widen university entrance qualification. Not only the high school graduates are qualified to attend university entrance examination, but also person with an equivalent education level, "in order to save the talent" (Hu, 2001).

\subsection{Avoiding a Completely Standardized Test, and Test Content Meeting the Demands of Traditional Academics}


It's in early time that standardized test was just introduced to China, when some scholars came to worry about the possibility of decline of traditional academics. Because standardized test produced by modern mass production adapt to the western scientific system and almost on the other side to Chinese traditional academics. Applying a standard of western subject classification to Chinese traditional academics and testing literacy with clear knowledge items will destroy Chinese traditional academics. There is no doubt that the traditional composition-oriented test has an advantage, otherwise why so many masters can be found in the Republican China. At present, the strongest blame is on test paper of Chinese in university entrance examination; actually a similar problem also exists in literature, history and philosophy. A reformation about education will be systematic, not only including properly adjust the system of elementary education curriculum, but adjust the subject content of university entrance examination to traditional academics. Once upon a time, some scholars had already appealed to "relieve the Chinese teaching from standardized test" (Zhou, 1999) and pointed out that it was unscientific and harmful to blindly object to traditional composition-oriented test.

\section{References}

Zhang, Y. Q. (2011). University Admission. The Study of Examination, 1, 3-8.

Liu, H. L. (2010). Talk about Wu Han's exceptionally Admitting by Tsinghua with 0 Score at Math. Journal of Tsinghua University, 4, 154-158.

Anonymous. (1931). National Tsinghua university undergraduate enrollment brochure. Tsinghua weekly, 35(11-12), 188-190.

Anonymous. (1934). National Tsinghua University Enrollment Calendar Year Undergraduate Students Admission Criteria. Tsinghua weekly, 41(13-14), 156-159.

Wen, L. M. (1992). Biography of Wen Yiduo. Beijing, China: People's Publishing House.

Sun, C. (2000). Century Poem Star. Jinan, China: Shandong University Press.

Wang, X. Z. (2000). The Historical Data of Peking University. Beijing, China: Peking University Press.

Anonymous. (1941). National Chung Cheng University Admissions Procedures. National chung cheng University School Magazine, 1(17), 7.

Li, L. (1983). Qingdao University's Striking Three Times in Two Years. Shandong University History Materials, $6,60-78$.

Hu, S. (2001). Hu Shi Diary. Hefei, China: Anhui Education Publishing House.

Su, S. B. (1998). Wang Hongzhi.Biography of WuHan. Shanghai, China: Shanghai People's Publishing House

Zhou, Z. K. (1999). Set Chinese Teaching Free From the Bondage of Standardized Tests. Curriculum, 3, 19-24.

\section{Copyrights}

Copyright for this article is retained by the author(s), with first publication rights granted to the journal.

This is an open-access article distributed under the terms and conditions of the Creative Commons Attribution license (http://creativecommons.org/licenses/by/3.0/). 